ARTICLE

\title{
Au-activated $\mathrm{N}$ motifs in non-coherent cupric porphyrin metal organic frameworks for promoting and stabilizing ethylene production
}

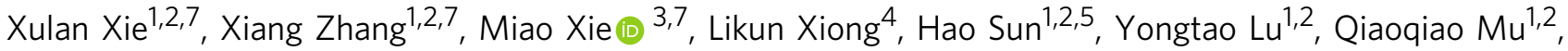 \\ Mark H. Rummeli ${ }^{1,2}$, Jiabin $\mathrm{Xu}^{3}$, Shuo $\mathrm{Li}^{3}$, Jun Zhong ${ }^{3}$, Zhao Deng (1) ${ }^{1,2}$, Bingyun Ma ${ }^{3}$, Tao Cheng (1) ${ }^{3 凶}$, \\ William A. Goddard III (i) ${ }^{6 凶}$ \& Yang Peng (iD) $1,2,5 \bowtie$
}

Direct implementation of metal-organic frameworks as the catalyst for $\mathrm{CO}_{2}$ electroreduction has been challenging due to issues such as poor conductivity, stability, and limited $>2 e^{-}$ products. In this study, Au nanoneedles are impregnated into a cupric porphyrin-based metalorganic framework by exploiting ligand carboxylates as the $\mathrm{Au}^{3+}$-reducing agent, simultaneously cleaving the ligand-node linkage. Surprisingly, despite the lack of a coherent structure, the Au-inserted framework affords a superb ethylene selectivity up to $52.5 \%$ in Faradaic efficiency, ranking among the best for metal-organic frameworks reported in the literature. Through operando X-ray, infrared spectroscopies and density functional theory calculations, the enhanced ethylene selectivity is attributed to Au-activated nitrogen motifs in coordination with the $\mathrm{Cu}$ centers for $\mathrm{C}-\mathrm{C}$ coupling at the metalloporphyrin sites. Furthermore, the $\mathrm{Au}$ inserted catalyst demonstrates both improved structural and catalytic stability, ascribed to the altered charge conduction path that bypasses the incoherent framework. This study underlines the modulation of reticular metalloporphyrin structure by metal impregnation for steering the $\mathrm{CO}_{2}$ reduction reaction pathway.

\footnotetext{
${ }^{1}$ Soochow Institute for Energy and Materials Innovations, College of Energy, Soochow University, Suzhou 215006, China. ${ }^{2}$ Key Laboratory of Advanced Carbon Materials and Wearable Energy Technologies of Jiangsu Province, Suzhou 215006, China. ${ }^{3}$ Institute of Functional Nano and Soft Materials (FUNSOM), Soochow University, Suzhou 215123, China. ${ }^{4}$ School of Chemical and Environmental Engineering, Shanghai Institute of Technology, Shanghai 201418, China. ${ }^{5}$ Jiangsu Engineering Laboratory of New Materials for Sewage Treatment and Recycling, Suzhou 215123, China. ${ }^{6}$ Materials and Process Simulation Center, Department of Chemistry, California Institute of Technology, Pasadena, CA 91125, United States. ${ }^{7}$ These contributed equally: Xulan Xie,

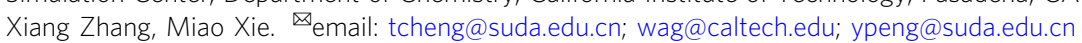


G rowing concern on the escalating anthropogenic carbon footprint urges all countries around the world to chart their carbon neutrality plans, in which using renewable electricity to convert $\mathrm{CO}_{2}$ into value-added chemicals is highly tempting and promising ${ }^{1-3}$. However, the high energy barrier for $\mathrm{CO}_{2}$ activation and the linear scaling relation for binding of intermediates constitute two intrinsic challenges for achieving high energy efficiency and product selectivity. This necessitates the development of high-performance electrocatalysts for $\mathrm{CO}_{2}$ reduction reactions $\left(\mathrm{CO}_{2} \mathrm{RR}\right)^{4-6}$. In this context, tremendous efforts have been devoted to the design and engineering of a wide category of $\mathrm{CO}_{2} \mathrm{RR}$ catalysts targeted for selectively producing $\mathrm{C}_{1}$ small molecules ${ }^{7-9}, C_{2+}$ hydrocarbons ${ }^{10,11}$, and oxygenated multicarbon products ${ }^{12,13}$, but significant advances remain to be made on optimizing catalyst activity, selectivity, and stability, as well as maximizing the techno-economic merit ${ }^{14,15}$. For that, a profound understanding of the catalytic process dictated by explicit catalyst structure is imperative for realizing productorientated catalyst design and development ${ }^{16-18}$.

Among the diverse electrocatalysts explored for $\mathrm{CO}_{2} \mathrm{RR}$, metalorganic frameworks (MOFs) represent a unique category with well-defined and tunable topologic/chemical structure comprising atomically isolated active sites that not only facilitate charge transfer and mass transport, but also help furnish mechanistic understanding on the catalytic process ${ }^{19,20}$. However, most of the reported MOFs, in their pristine form, produce mainly $\mathrm{C}_{1}$ products such as $\mathrm{CO}, \mathrm{HCOOH}$, and $\mathrm{CH}_{4}{ }^{7,21,22}$. This probably arises from the distance between separated active sites in the reticular network that prohibit efficient $\mathrm{C}-\mathrm{C}$ coupling, which otherwise would be more advantageous if the active sites were adjacent to each other in close proximity ${ }^{23}$. As multi-carbon products are often the development target ${ }^{15}$, a key question is how to encourage $\mathrm{C}-\mathrm{C}$ coupling on the atomically isolated metal sites inside the reticular network?

A further issue of the MOF-based $\mathrm{CO}_{2} \mathrm{RR}$ electrocatalysts lies in their instability in both alkaline and electrochemical conditions ${ }^{24,25}$. Electron transport in the standalone MOFs typically traffics through the node-linker network, which can be demolished under the tough electrolytic condition of $\mathrm{CO}_{2} \mathrm{RR}^{26,27}$. In fact, many previous studies on MOFs as $\mathrm{CO}_{2} \mathrm{RR}$ catalysts have mainly utilized them as the structural precursor or redox mediator after going through post-synthetic treatments for structural mutation and stabilization ${ }^{24,28,29}$. These measures, however, would unavoidably corrupt the well-defined topologic and molecular structure of MOFs, and thus curtail mechanistic understanding ${ }^{30}$. As a result, it is critical to find appropriate techniques to stabilize MOFs while simultaneously boosting redox charge transfer toward selective hydrocarbon synthesis in order to take full advantage of their structural merits ${ }^{20}$.

Impregnation of metal nanostructures into the reticular framework has been demonstrated as an effective way to endow desired functionalities (e.g., conductivity, photoactivity, and catalytic activity) to $\mathrm{MOFs}^{31-33}$. When adapted to $\mathrm{CO}_{2} \mathrm{RR}$, this allows a tandem pathway for producing $>2 \mathrm{e}^{-}$products to be established by exploiting different active sites from different structural moieties ${ }^{34}$. In this case, the incorporated metals might effectively alter the charge distribution and conduction path within the MOF framework to further improve the $\mathrm{CO}_{2} \mathrm{RR}$ behavior.

Herein, we set out to impregnate $\mathrm{Au}$ nanoneedles into the Zirconium-based PCN-222 MOF, which has isolated cupric porphyrin centers, to assess its performance as a $\mathrm{CO}_{2} \mathrm{RR}$ catalyst. The idea is to exploit the embedded $\mathrm{Au}$ as a high-efficiency $\mathrm{CO}$ generator, and the $\mathrm{Cu}-\mathrm{N}_{4}$ active sites in the metalloporphyrins to relay and convert $\mathrm{CO}$ further into $>2 \mathrm{e}^{-}$hydrocarbon products with high selectivity (Fig. 1). For control studies, we also synthesize the same PCN-222 MOFs with $\mathrm{Au}$ nanoparticles deposited on the surface exterior, as well as MOFs w/o Au and $\mathrm{Cu}$ motifs, to interrogate the associated reaction mechanisms. We show that despite the possession of an incoherent framework, the Au-impregnated MOF produces ethylene in a high selectivity that has been rarely seen for such materials. Combining operando synchrotron X-ray spectroscopy, in-situ IR, and DFT modeling, we ascribe the $\mathrm{C}-\mathrm{C}$ coupling to a tandem mechanism, where $\mathrm{CO}$ generated from the impregnated Au nanoneedles are adducted to ${ }^{*} \mathrm{CHO}$ at the Au-activated $\mathrm{N}$ sites, and the improved structural and catalytic stability to an altered charge conduction path that bypasses the incoherent framework.

\section{Results}

Catalyst synthesis and characterization. The syntheses and characterizations of Zirconium-based PCN-222 (PCN = porous coordination networks) MOFs utilizing tetrakis(4-carboxyphenyl) porphyrin (TCPP) ligands without and with metalloporphyrin $\mathrm{Cu}$ centers (designated as PCN-222 and PCN-222(Cu), respectively) are depicted in the Supplementary note 1 and Supplementary Figs. 1-6. Two synthetic protocols were adopted to affix/ impregnate Au nanostructures onto/into the PCN-222(Cu) MOF, exhibiting an ellipsoidal morphology (Fig. 2a, d, g). Specifically, when chlorauric acid was reduced by carboxylic groups contained in the MOF ligands at properly adjusted aqueous $\mathrm{pH}$, $\mathrm{Au}$ nanoneedles (AuNN) were embedded into the PCN-222(Cu) ellipsoids in alignment with the MOF pore channels. These samples are denoted as AuNN@PCN-222(Cu) (Fig. 2b, e, h). The average diameter of the implanted AuNN is about $10 \pm 2 \mathrm{~nm}$, much bigger than that of the larger hexagonal pore channels $(3.7 \mathrm{~nm})$ illustrated in Supplementary Fig. 1. Thus, we presume that during the growth of the AuNN, part of the PCN-222(Cu) framework was eroded by cleaving the node-ligand linkage as sketched in Fig. 1. Similar observation was also made by Duan et $\mathrm{al}^{35}$ when inserting $\mathrm{Au}$ nanowires into MOF-545 in water. In an aqueous environment, the carboxylic groups from the ligand-node redox couple in the MOF can be attacked by the $\mathrm{Au}^{3+}$ oxidizer, which in turn cleaves the ligand-node linkage. Without the extra addition of reducing agent, the carboxylates are solely responsible for reducing $\mathrm{Au}^{3+}$ to $\mathrm{Au}^{0}$. Alternately, when the chlorauric acid was reduced by the extra added $\mathrm{NaBH}_{4}$ in ethanol, Au nanoparticles (AuNP) were deposited instantly on the surface of the PCN$222(\mathrm{Cu})$ ellipsoids (Fig. 2c, f, i), with the resulting products denoted as AuNP@PCN-222(Cu).

Figure $2 \mathrm{j}$ compares the XRD patterns of $\mathrm{PCN}-222(\mathrm{Cu})$, AuNN@PCN-222(Cu), and AuNP@PCN-222(Cu). We see that the two Au peaks of AuNN@PCN-222(Cu) at $38^{\circ}$ and $44^{\circ}$ (corresponding to (111) and (200) planes, respectively) are much sharper than those of the AuNP@PCN-222(Cu), indicating that the as-formed Au nanoneedles are better crystalized due to slower growth rate. In contrast, the deposition of $\mathrm{Au} N \mathrm{NP}$ on $\mathrm{PCN}-222(\mathrm{Cu})$ by $\mathrm{NaBH}_{4}$ is much faster, resulting in numerous but smaller $\mathrm{Au}$ crystallites. At lower $2 \theta$ angles, the serial MOF peaks from AuNN@PCN-222(Cu) are not as prominent as those of AuNP@PCN-222(Cu), implying that the reticular framework of AuNN@PCN-222(Cu) is relatively disordered due to the ligand carboxylates reacting with chlorauric acid. This change of coordination network in AuNN@PCN-222(Cu) further leads to a notably different IR spectrum compared to those of AuNP@PCN-222(Cu) and PCN-222(Cu) (Fig. 2k). For AuNN@PCN-222(Cu), both the asymmetric and symmetric stretching of $\mathrm{COO}^{-}$at 1600 and $1416 \mathrm{~cm}^{-1}$, respectively, are drastically weakened, whereas the $\mathrm{C}=\mathrm{N}$ vibration at $1542 \mathrm{~cm}^{-1}$ is intensified and redshifted. These could be attributed to the cleavage of the nodelinker connection, as well as the structural distortion of the metalloporphyrin ring upon Au impregnation. All samples displayed 


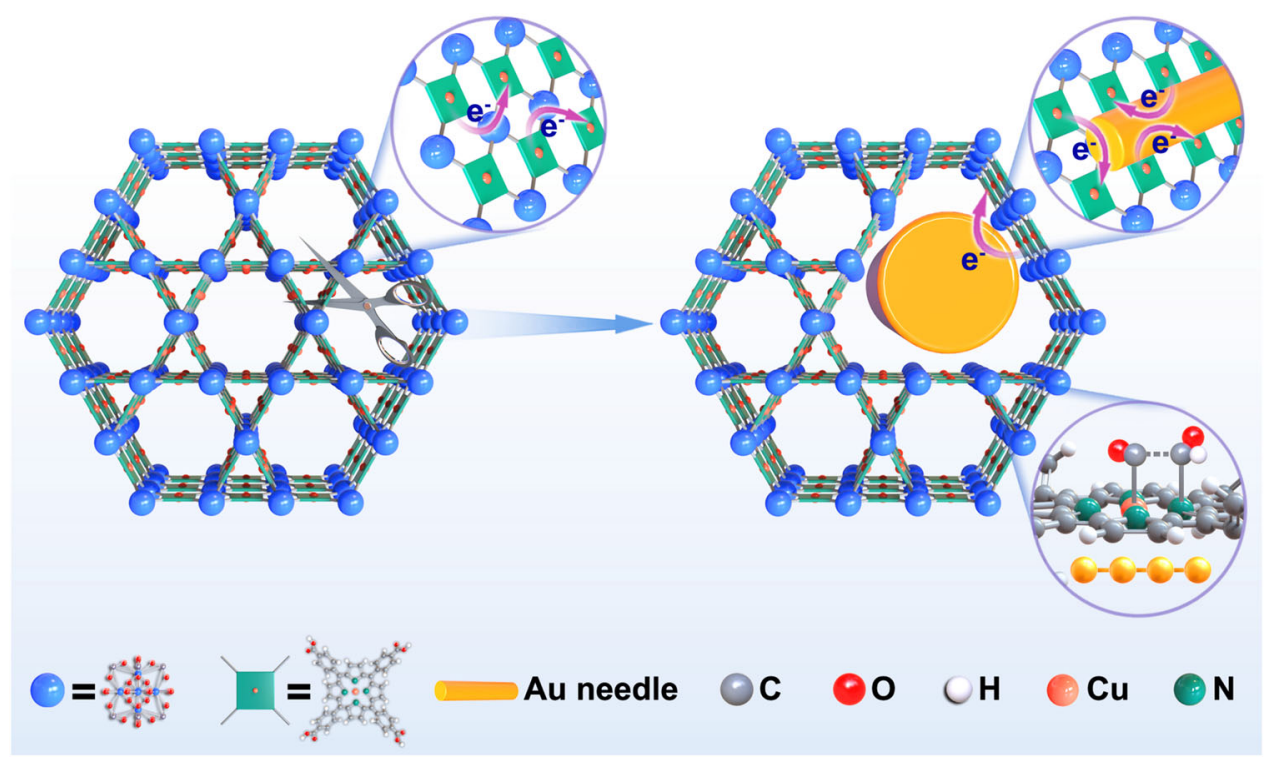

Fig. 1 Schematic illustration of the catalytic mechanism. Impregnation of Au nanoneedles into PCN-222(Cu) with cleaved ligand-node linkage to alter the charge conduction path and steer the $\mathrm{CO}_{2} \mathrm{RR}$ pathway.

a strong absorption at $1000 \mathrm{~cm}^{-1}$ arising from $\mathrm{Cu}-\mathrm{N}$ stretching in metalloporphyrins.

The UV-vis spectra of PCN-222(Cu), AuNN@PCN-222(Cu), and AuNP@PCN-222(Cu) all exhibit only two Q bands, affirming the $\mathrm{Cu}$ coordination in porphyrin centers (Fig. $2 \mathrm{l})^{14}$. The extra absorption band at $650 \mathrm{~nm}$ on AuNN@PCN-222(Cu) can be ascribed to the longitudinal surface plasma resonance (LSPR) of the well-crystalized Au nanoneedles, which is largely governed by the aspect ratio $^{36}$. On the other side, the shoulder of the porphyrin $\pi \sim \pi^{*}$ transition band observed for PCN-222(Cu) and AuNP@PCN-222(Cu) is missing in the spectrum of AuNN@PCN-222(Cu), further confirming a structural distortion of the porphyrin ring ${ }^{37}$, in resonance with the altered $\mathrm{C}=\mathrm{N}$ vibration observed in IR. Lastly, despite the different reaction protocol and composite structure, elemental analyses by Inductively Coupled Plasma Emission Spectrometry (ICP-ES) revealed similar mass ratios of $\mathrm{Au}, \mathrm{Cu}$, and $\mathrm{Zr}$ in both AuNN@PCN222(Cu) and AuNP@PCN-222(Cu) (Supplementary Table 1).

Electrochemical reduction of $\mathbf{C O}_{2}$. The $\mathrm{CO}_{2} \mathrm{RR}$ performances of PCN-222(Cu),AuNN@PCN-222(Cu), and AuNP@PCN-222(Cu) were investigated in an $\mathrm{H}$-cell containing $0.1 \mathrm{M} \mathrm{KHCO}_{3}$ saturated with continuously purged $\mathrm{CO}_{2}$. Linear scanning voltammograms show that at potentials lower than $-0.5 \mathrm{~V}$ (vs. RHE, all potentials are referred to this format hereafter) the current density of AuNN@PCN-222(Cu) is slightly lower than that of AuNP@PCN$222(\mathrm{Cu})$, but higher than that of PCN-222(Cu) (Supplementary Fig. 7), which is further corroborated by electrochemical impedance measurements at $-1.2 \mathrm{~V}$, revealing the charge transfer resistance $\left(\mathrm{R}_{\mathrm{ct}}\right)$ in the order of AuNP@PCN-222 $(\mathrm{Cu})<$ AuNN@PCN-222(Cu) < PCN-222 $(\mathrm{Cu})$ (Supplementary Fig. 8). Considering that on AuNP@PCN-222(Cu) the Au nanoparticles are mostly exposed at the surface and the MOF framework is more integral and coherent, the higher charge transfer kinetics could arise from its high electric conductivity combined with its overall catalytic potency (including both HER and $\mathrm{CO}_{2} \mathrm{RR}$ ).

Potentiostatic measurements by sequentially decreasing the applied potentials from -0.8 to $-1.6 \mathrm{~V}$ showed that AuNN@PCN-222(Cu) produced mainly $\mathrm{C}_{2} \mathrm{H}_{4}$ with the maximal FE of $52.5 \%$ observed at $-1.2 \mathrm{~V}$ (Fig. 3a). This is, to our best knowledge, among the best seen for MOFs reported in the literature (Supplementary Table 2). For AuNP@PCN-222(Cu), $\mathrm{CO}$ constituted the major reduction product over the whole potential range tested, with the FE decreasing with the applied potential from $55.5 \%$ at $-0.8 \mathrm{~V}$ to $30.7 \%$ at $-1.6 \mathrm{~V}$ (Fig. $3 \mathrm{~b}$ ). The high CO yield observed on AuNP@PCN-222(Cu) can be directly related to the surface-exposed $\mathrm{Au}$ nanoparticles. In a stark contrast, $\mathrm{PCN}-222(\mathrm{Cu})$ produced mainly $\mathrm{H}_{2}$ throughout the entire potential range (Fig. 3c). Above all, the FEs of $\mathrm{C}_{2} \mathrm{H}_{4}$ production on AuNN@PCN-222(Cu) are significantly higher than on Au-NP@PCN-222(Cu) and PCN-222(Cu), implying a different mechanism for ethylene formation.

Partial current density plots showed the yield rate of $\mathrm{C}_{2} \mathrm{H}_{4}$ on AuNN@PCN-222 $(\mathrm{Cu})$ was nearly three-fold higher than that on AuNP@PCN-222(Cu) and PCN222(Cu) (Supplementary Fig. 9a), indicating that $\mathrm{Au}$ nanoneedles inside the MOF help to dramatically boost the kinetics of ethylene production. The difference in $\mathrm{CH}_{4}$ production between AuNN@PCN-222(Cu) and AuNP@PCN-222(Cu) was not significant, and both were marginally higher than that on PCN-222(Cu), suggesting that the $\mathrm{Au}$ nanostructures exert limited influence on methane production (Supplementary Fig. 9b). On the other hand, the CO production on AuNP@PCN-222(Cu) was almost four times of that on AuNN@PCN-222(Cu) at potentials lower than $-1.2 \mathrm{~V}$ (Supplementary Fig. 9c), at which $\mathrm{C}_{2} \mathrm{H}_{4}$ reached the highest FE on the latter (Fig. 3a). This suggests that on AuNP@PCN$222(\mathrm{Cu}) \mathrm{CO}$ generated by $\mathrm{Au}$ nanoparticles are unlikely to reenter the $\mathrm{CO}_{2} \mathrm{RR}$ pathway to yield $>2 \mathrm{e}^{-}$products. We also noted an abnormal drop of $\mathrm{CO}$ yield from -1.0 to $-1.2 \mathrm{~V}$ on AuNN@PCN-222(Cu) (Supplementary Fig. 9c), possibly due to the overwhelming consumption of $\mathrm{CO}$ to yield $\mathrm{C}_{2} \mathrm{H}_{4}$ at these potentials. Thus, the production of $\mathrm{C}_{2} \mathrm{H}_{4}$ on AuNN@PCN$222(\mathrm{Cu})$ presumably follows a tandem path, in which $\mathrm{CO}$ generated by AuNN are further reduced on the metalloporphyrin sites. This viewpoint was further reinforced by a series of control experiments with MOFs containing free-base porphyrins and different AuNN loading, as detailed in Supplementary note 2 and Supplementary Figs. 10, 11.

Next, the electrocatalytic stabilities of AuNN@PCN-222(Cu), AuNP@PCN-222(Cu), and PCN-222(Cu) were compared by conducting chronoamperometric i-t tests for a duration of $10 \mathrm{~h}$ (Fig. 3d-f). Impressively, AuNN@PCN-222(Cu) manifested a 
a

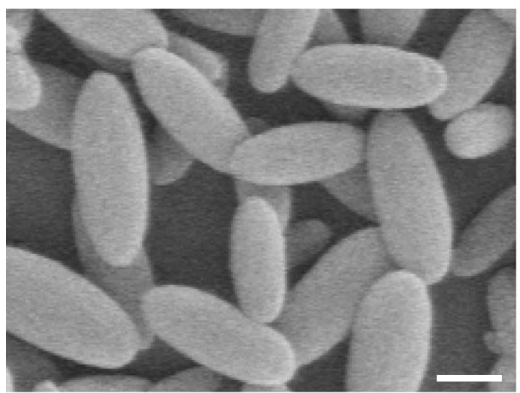

d

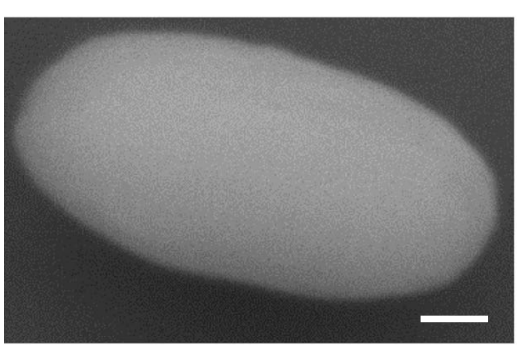

g
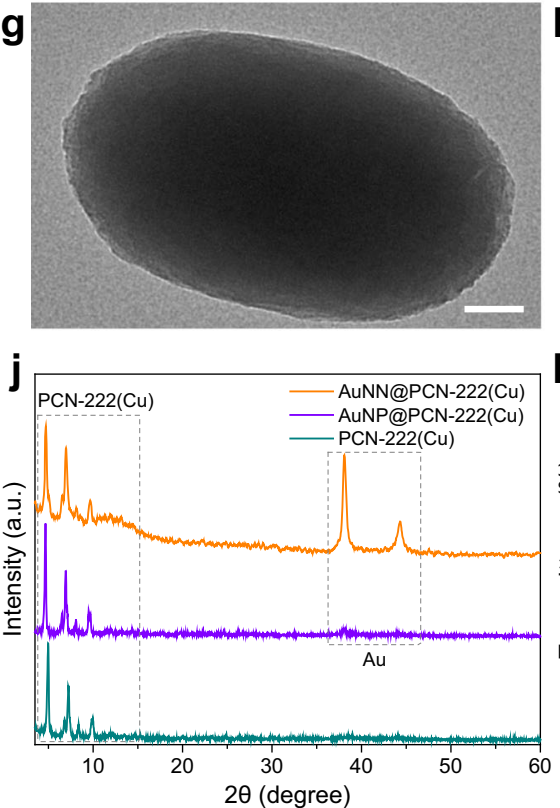
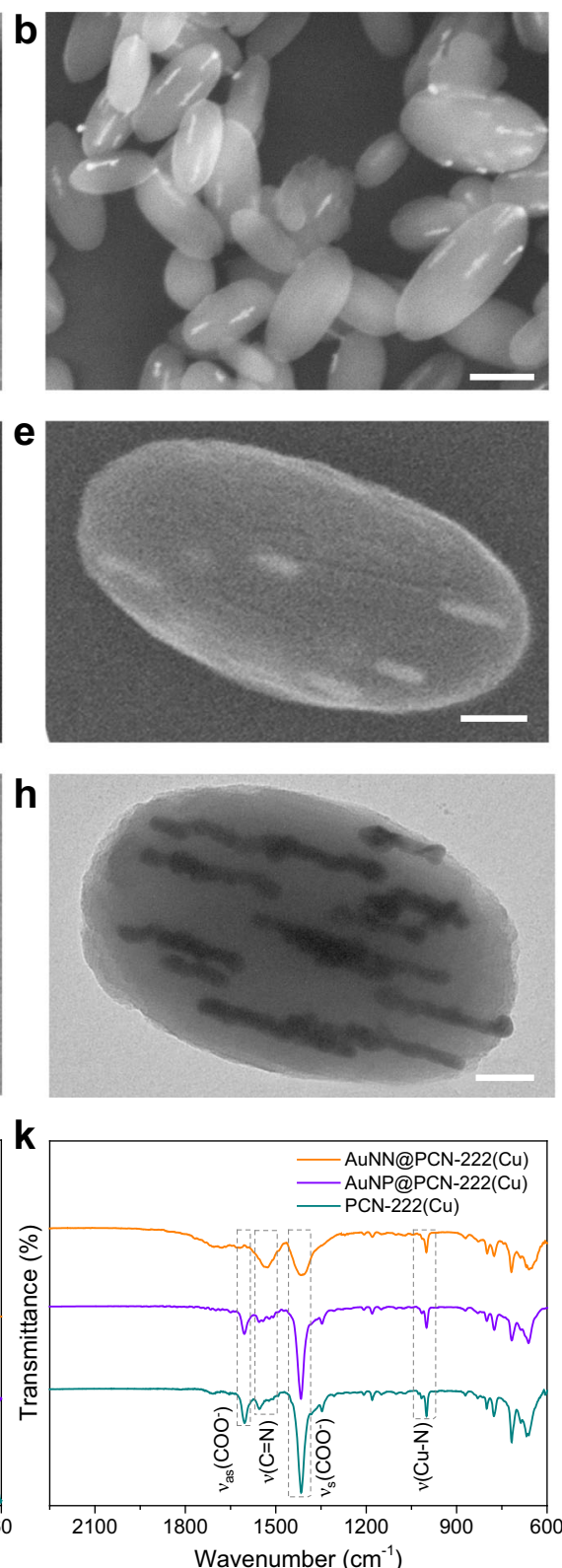
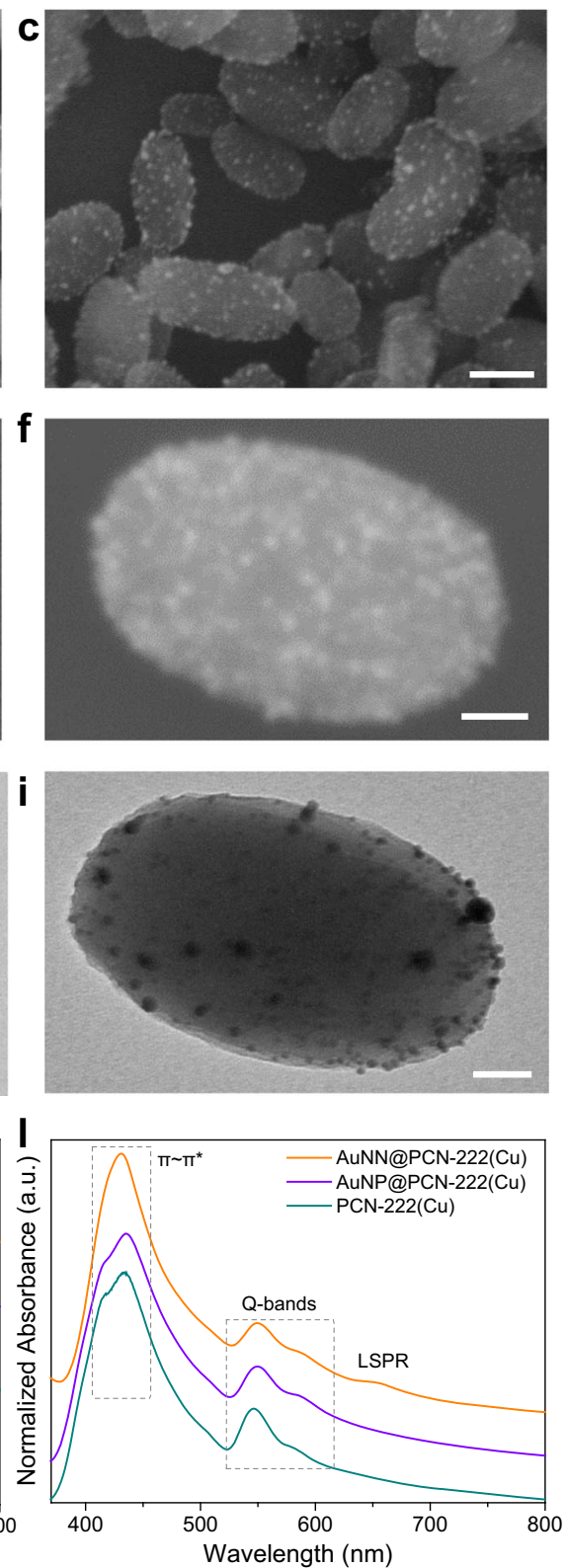

Fig. 2 Structural characterizations of the three PCN-222(Cu) catalysts with and $\mathbf{w} /$ o Au. a-c low-magnification, $\mathbf{d}-\mathbf{f}$ high-magnification SEM, and $\mathbf{g}-\mathbf{i}$ TEM images of PCN-222(Cu), AuNN@PCN-222(Cu), and AuNP@PCN-222(Cu), respectively. $\mathbf{j}-\mathbf{I}$ XRD, FT-IR, and UV-vis spectra of the above three catalysts. The scale bars are $250 \mathrm{~nm}(\mathbf{a}-\mathbf{c})$, and $50 \mathrm{~nm}(\mathbf{d}-\mathbf{i})$.

very stable $\mathrm{C}_{2} \mathrm{H}_{4}$ yield during the first $5 \mathrm{~h}$ with a nearly constant FE of $~ 50 \%$. After that, it gradually decreased to $41 \%$ at the end of the 10-h test, accompanied with an incremental growth in $\mathrm{H}_{2}$ production (Fig. 3d). On AuNP@PCN-222(Cu), the CO production was nearly constant, concomitant with the decrease in $\mathrm{C}_{2} \mathrm{H}_{4}$ yield and increase in $\mathrm{H}_{2}$ production (especially in the first $5 \mathrm{~h}$, Fig. 3e). As for $\mathrm{PCN}-222(\mathrm{Cu}), \mathrm{H}_{2}$ production was dominant throughout the test and continually rose at the expense of $\mathrm{C}_{2} \mathrm{H}_{4}$ and $\mathrm{CO}$ (Fig. 3f). The varying trend of $\mathrm{C}_{2} \mathrm{H}_{4}, \mathrm{CO}$, and $\mathrm{H}_{2}$ evolution observed on these catalysts suggest different structural mutation during $\mathrm{CO}_{2} \mathrm{RR}$, which will be closely inspected by postmortem and operando studies as detailed below.

Post-mortem and operando characterizations. The catalyst morphologies after one hour of $\mathrm{CO}_{2} \mathrm{RR}$ at $-1.2 \mathrm{~V}$ were examined using SEM and TEM (Fig. 4). SEM images show while AuNN@PCN-222(Cu) well retained its original ellipsoidal morphology, AuNP@PCN-222(Cu) and PCN-222(Cu) collapsed into irregular shapes (Fig. $4 a-c$ vs. Supplementary Fig. 12), which are better visualized by the high-angle annular dark fieldscanning transmission electron microscopy (HAADF-STEM) images shown in Fig. 4d-i. On the post-electrolytic AuNN@PCN$222(\mathrm{Cu})$ sample, Au nanoneedles impregnated into the PCN$222(\mathrm{Cu})$ matrix remained mostly intact, and $\mathrm{Cu}$ was still homogeneously dispersed (Fig. 4g). By contrast, numerous aggregated metal particles were observed on the post-electrolytic AuNP@PCN-222(Cu) and PCN-222(Cu) samples. EDXmapping revealed that the nanoparticles evolved from AuNP@PCN-222(Cu) contained both $\mathrm{Cu}$ and $\mathrm{Au}$ in segregated phases (Fig. 4h). Further analyses using HR-TEM revealed characteristic $\mathrm{Au}(111)$ lattice fringes with a d-spacing of $0.232 \mathrm{~nm}$ on the Au nanoneedles of post-electrolytic AuNN@PCN-222(Cu) without any $\mathrm{Cu}$-related facets (Fig. 4j). Whereas $\mathrm{Cu}(111)$ and $\mathrm{Cu}(100)$ facets respectively with d-spacings of 0.208 and $0.185 \mathrm{~nm}$ 

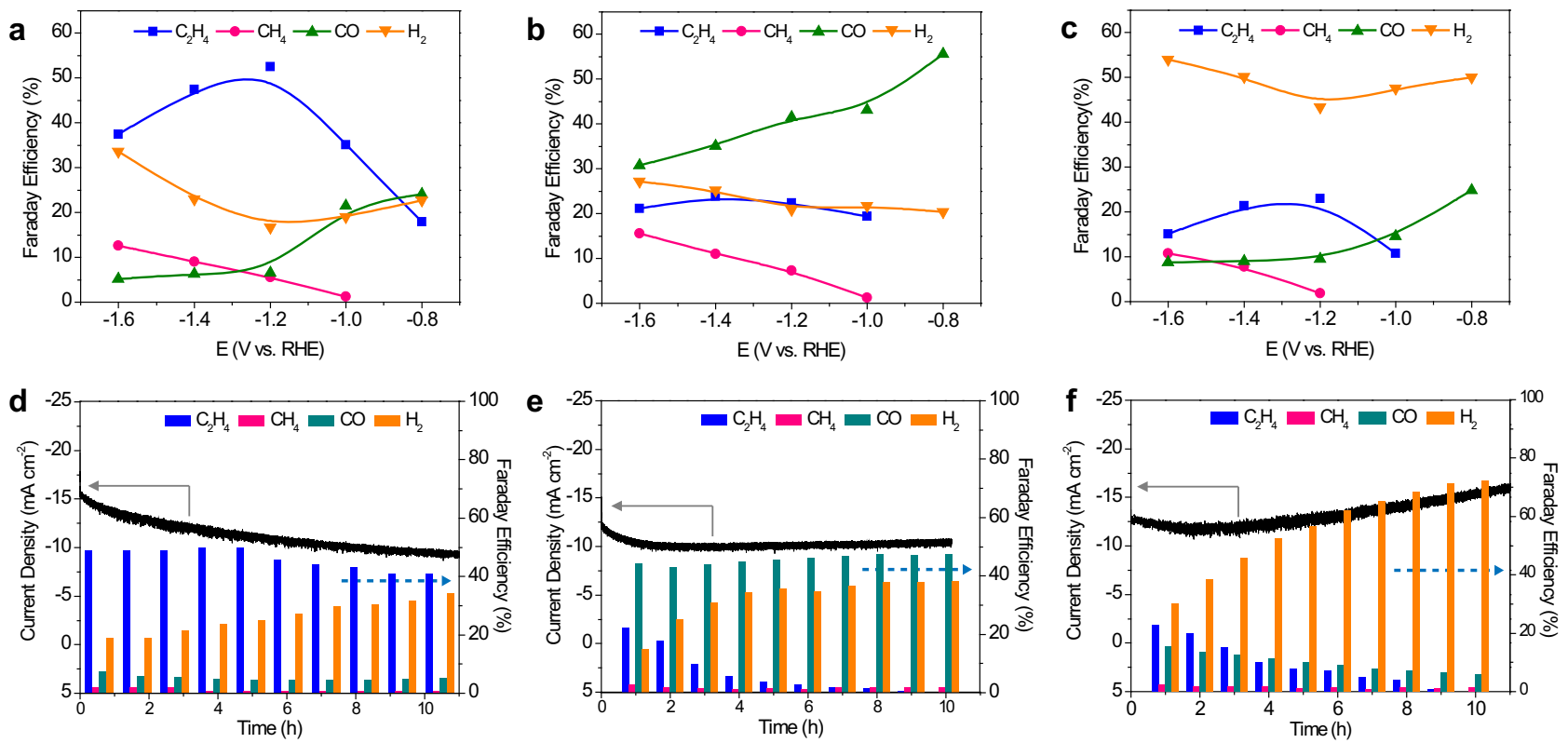

Fig. $3 \mathbf{C O}_{2}$ RR performances of the catalysts. a-c FEs of various reduction products for AuNN@PCN-222(Cu), AuNP@PCN-222(Cu), and PCN-222(Cu), respectively, at different potentials. d-f Chronoamperometric stability tests for AuNN@PCN-222(Cu), AuNP@PCN-222(Cu), and PCN-222(Cu) at -1.2, -1.0 , and $-1.2 \mathrm{~V}$, respectively, with the gaseous products measured every $1 \mathrm{~h}$.
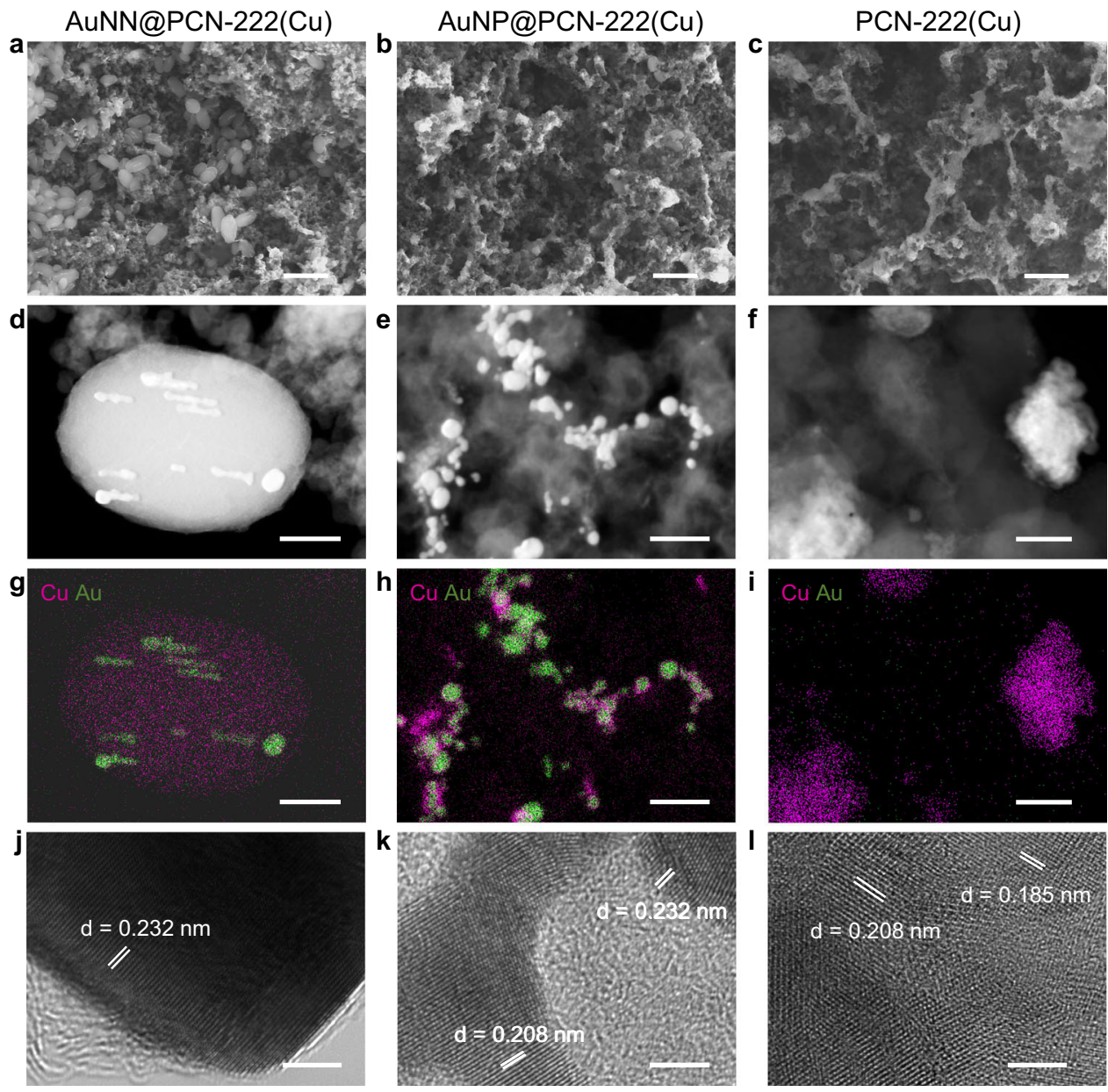

Fig. 4 Microstructural characterizations of the three catalysts after $\mathbf{1} \mathbf{h}$ test of $\mathbf{C O}_{\mathbf{2}} \mathbf{R R}$. a-c $S E M, \mathbf{d}-\mathbf{f} \mathrm{STEM}$, $\mathbf{g}$-i EDX-mapping, $\mathbf{j}$-I HR-TEM images of AuNN@PCN-222(Cu), AuNP@PCN-222(Cu), and PCN-222(Cu), respectively. The scale bars are 500 nm (a-c), 100 nm (d-i), and 3 nm (j-I). 

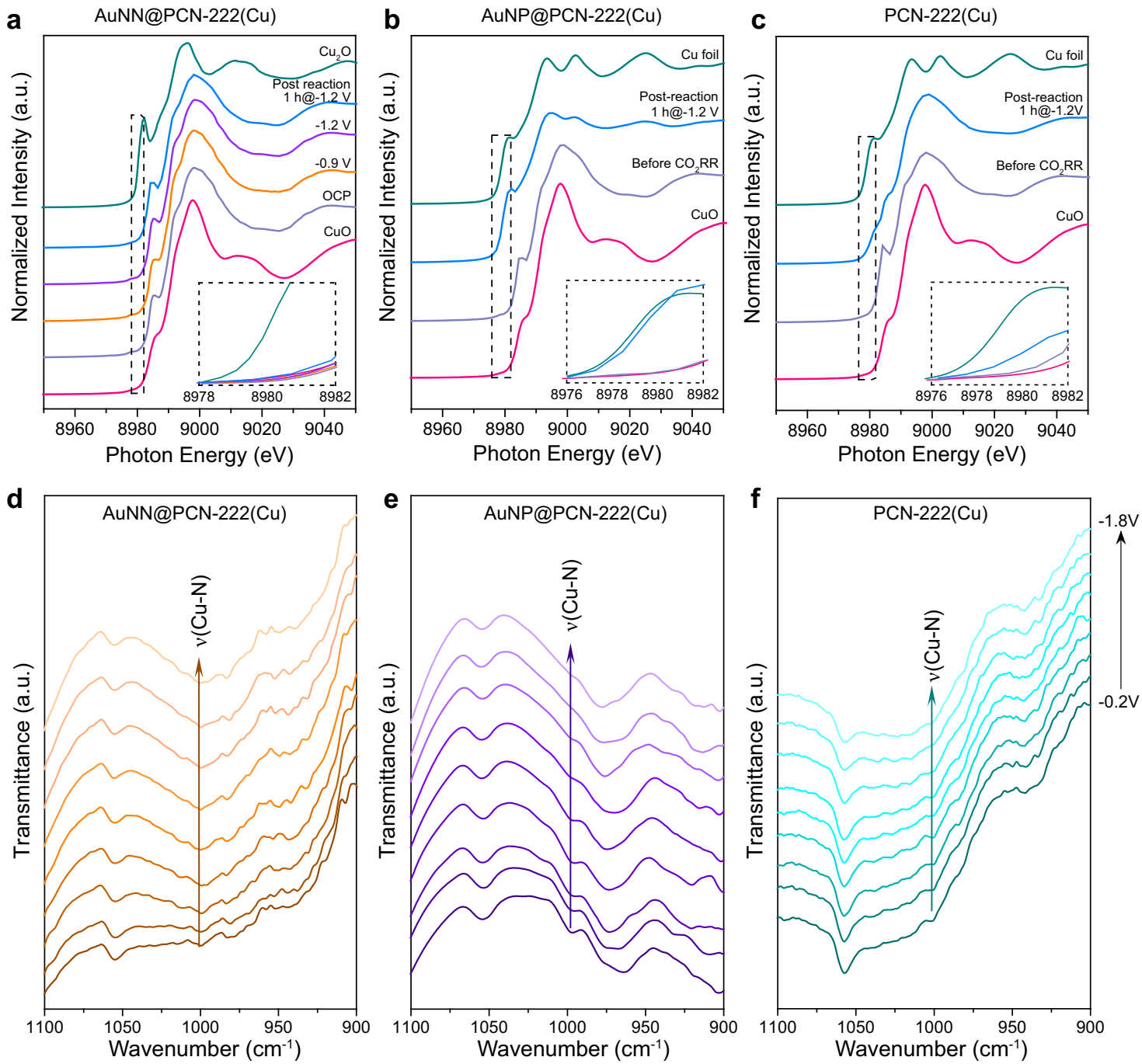

Fig. 5 XANES and IR characterizations on the structural stability of catalysts. a Operando Cu K-edge XANES spectra taken on AuNN@PCN-222(Cu) at varying potentials and after $1 \mathrm{~h} \mathrm{CO} \mathrm{CO}_{2} \mathrm{RR}$ test at $-1.2 \mathrm{~V}$. b,c Cu K-edge XANES spectra acquired on AuNP@PCN-222(Cu) and PCN-222(Cu) before and after $1 \mathrm{~h} \mathrm{CO}_{2} \mathrm{RR}$ test at $-1.2 \mathrm{~V}$. d-f Serial ATR-SEIRAS spectra acquired by ramping down the potential from -0.2 to $-1.8 \mathrm{~V}$ on AuNN@PCN-222(Cu),

AuNP@PCN-222(Cu) and PCN-222(Cu), respectively.

were observed on post-electrolytic PCN-222(Cu) (Fig. 41), both $\mathrm{Au}(111)$ and $\mathrm{Cu}(111)$ lattice fringes, as expected, were visualized on the post-electrolytic AuNP@PCN-222(Cu) sample (Fig. 4k).

Moreover, both SEM and TEM images taken on AuNN@PCN$222(\mathrm{Cu})$ after $10 \mathrm{~h}$ of electrolytic $\mathrm{CO}_{2} \mathrm{RR}$ at $-1.2 \mathrm{~V}$ showed that the integrity of the MOF structure was still mostly retained (Supplementary Fig. 13), despite of a few irregular ellipsoids. This is in great contrast to the completely collapsed morphology of AuNP@PCN222(Cu) and PCN222(Cu) after just $1 \mathrm{~h}$. Overall, the above microscopic observations strongly attest to the structural durability of AuNN@PCN-222(Cu) in comparison to AuNP@PCN$222(\mathrm{Cu})$ and $\mathrm{PCN} 222(\mathrm{Cu})$ during $\mathrm{CO}_{2} \mathrm{RR}$.

Operando X-ray absorption spectroscopy (XAS) was used to track the evolution of $\mathrm{Cu}$ valence and coordination states in AuNN@PCN-222(Cu) during $\mathrm{CO}_{2} \mathrm{RR}$ to further support the above point of view. Previous studies have shown $\mathrm{Cu}$ clusters can be reversibly reduced in the $\mathrm{Cu}-\mathrm{N}_{4}$ complexes prepared pyrolytically ${ }^{38}$ or molecularly ${ }^{39}$, but this is not the case in the current study. In the in-situ X-ray absorption near-edge spectra (XANES) with $\mathrm{CuO}$ and $\mathrm{Cu}_{2} \mathrm{O}$ as references, the oxidation state of $\mathrm{Cu}^{2+}$ at the metalloporphyrin centers barely changed when the applied potential was ramped from OCP to $-1.2 \mathrm{~V}$ (Fig. 5a).
Furthermore, the XANES spectrum taken on AuNN@PCN$222(\mathrm{Cu})$ immediately after $10 \mathrm{~h}$ of stability test showed only a marginally reduced $\mathrm{Cu}$ state close to +2 , confirming that the $\mathrm{Cu}$ centers were mostly unchanged during the prolonged electrolysis (Supplementary Fig. 14). These results are in good resonance with the structural stability witnessed by microscopies. In comparison, the adsorption edges of post-electrolytic AuNP@PCN-222(Cu) and PCN-222(Cu) downshifted closer to that of the reference $\mathrm{Cu}$ foil (Fig. 5b, c), suggesting that $\mathrm{Cu}^{2+}$ centers in these samples were reduced, which is further justified by the $\mathrm{Cu}-\mathrm{Cu}$ bonding in the Fourier-transform extended X-ray absorption fine structure (FT-EXAFS, Supplementary Figs. 15,16). We note that from both the XANES and FT-EXAFS results the metalloporphyrin $\mathrm{Cu}$ centers in AuNP@PCN-222(Cu) are more easily to be reduced, likely due to the higher current densities passing through the MOF reticular network.

The structural stability of the catalysts during $\mathrm{CO}_{2} \mathrm{RR}$ was further examined by in-situ attenuated-total-reflection surfaceenhanced infrared spectroscopy (ATR-SEIRAS) with the applied potential swept from -0.2 to $-1.8 \mathrm{~V}$ (Fig. $5 \mathrm{~d}-\mathrm{f}$ ). Note that the prominent stretching mode of $\mathrm{Cu}-\mathrm{N}$ at $1000 \mathrm{~cm}^{-1}$ (Fig. $2 \mathrm{k}$ ) can be used as a good landmark to index the stability of the 

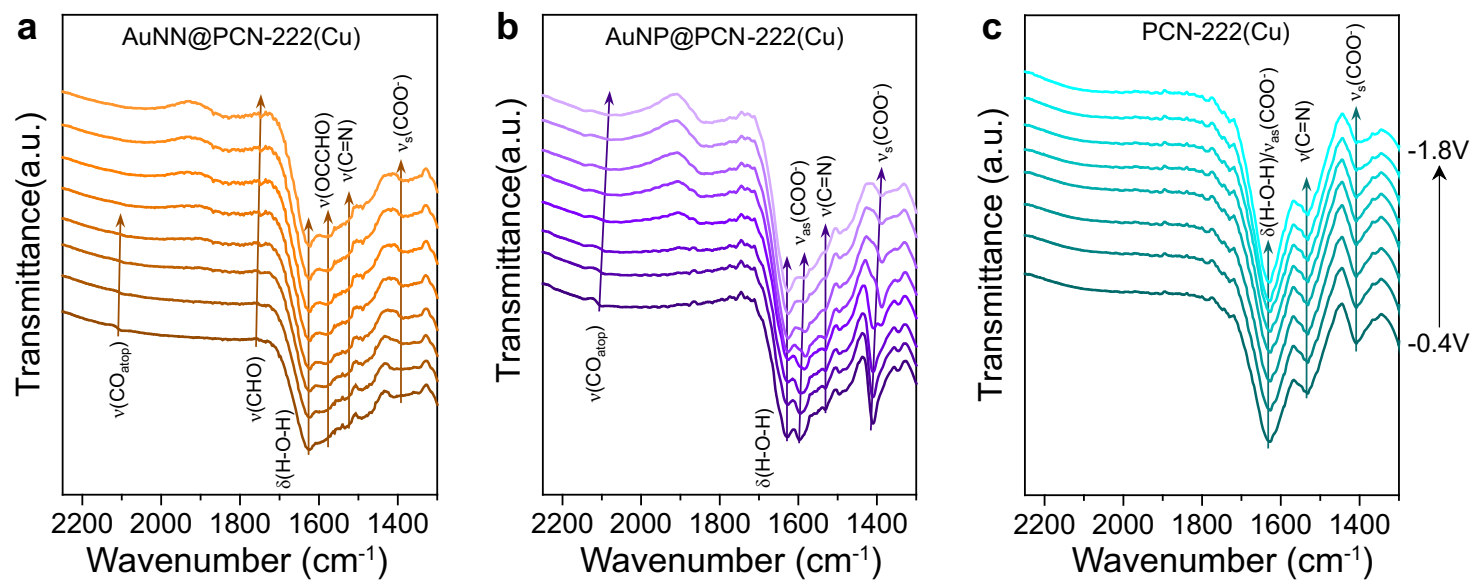

Fig. 6 Operando ATR-SEIRAS spectra. a AuNN@PCN-222(Cu), b AuNP@PCN-222(Cu), and c PCN-222(Cu). All spectra were recorded while ramping down the applied potential from -0.4 to $-1.8 \mathrm{~V}$ to monitor the evolution of intermediates binding.

metalloporphyrin Cu centers. For AuNN@PCN-222(Cu), the Cu$\mathrm{N}$ peak was persistent throughout the entire potential range (Fig. 5d), whereas those of AuNP@PCN-222(Cu) and PCN$222(\mathrm{Cu})$ decayed gradually with increasing bias. Particularly, at $-1.8 \mathrm{~V}$, the Cu-N vibration on AuNP@PCN-222(Cu) was mostly disappeared (Fig. 5e), echoing its liability for reduction as aforementioned. Taken together, both the above XAS and IR spectroscopic observations attest to the better durability of AuNN@PCN-222(Cu) under $\mathrm{CO}_{2} \mathrm{RR}$ conditions, coinciding with its good electrocatalytic stability in $\mathrm{C}_{2} \mathrm{H}_{4}$ production.

In-situ ATR-SEIRAS was also exploited to trace the evolution of reaction intermediates during $\mathrm{CO}_{2} \mathrm{RR}$ from -0.4 to $-1.8 \mathrm{~V}$ (Fig. 6). On AuNN@PCN-222(Cu), the absorption peak at $2108 \mathrm{~cm}^{-1}$ can be attributed to the $\mathrm{C} \equiv \mathrm{O}$ stretching of adsorbed $* \mathrm{CO}$ atop Au active sites $\left(\mathrm{CO}_{\text {atop }}\right)^{40}$, which gradually decayed and disappeared after $-0.8 \mathrm{~V}$, implying the consumption of $\mathrm{CO}_{\text {atop }}$ at more negative bias for hydrocarbon production (Fig. 6a). This coincides with the $\mathrm{CO}$ current plot shown in Supplementary Fig. 9c, where a drop of current density occurred at $-1.0 \mathrm{~V}$. The peak at $1750 \mathrm{~cm}^{-1}$, intensifying with decreasing potentials, is possibly related to the ${ }^{*} \mathrm{CHO}$ absorbed on the metalloporphrins ${ }^{10}$. The ${ }^{*} \mathrm{CHO}$ could serve as the precursor for subsequent $\mathrm{CH}_{4}$ production, as well as the formation of $* \mathrm{CO}-\mathrm{CHO}$ by adducting one $\mathrm{CO}$ from $\mathrm{Au}$, which is evidenced by the intensifying absorption band at $1578 \mathrm{~cm}^{-1} 41$. The absorption band at $1532 \mathrm{~cm}^{-1}$, as aforementioned, is ascribed to the stretching mode of $\mathrm{C}=\mathrm{N}$ within the porphyrin groups. Collectively, the serial IR spectra acquired on AuNN@PCN-222(Cu) further support the tandem mechanism of $\mathrm{C}_{2} \mathrm{H}_{4}$ formation, where $\mathrm{CO}$ generated from AuNN could be adducted to ${ }^{*} \mathrm{CHO}$ on the metalloporphyrins, followed by subsequent PCET (proton-coupled electron transfer) processes for hydrogenation ${ }^{14}$.

In the sequential IR spectra of AuNP@PCN-222(Cu), the scenario of intermediates binding is quite different (Fig. 6b). Firstly, the peak of $\mathrm{CO}_{\text {atop }}$ is more persistent through the applied bias, which is consistent with the observed high $\mathrm{CO}$ yield and indicates their consumption to form $>2 \mathrm{e}^{-}$products could be less significant. Secondly, the intermediate of $* \mathrm{CO}-\mathrm{CHO}$ previously observed on AuNN@PCN-222(Cu) with the intensity increasing with decreasing potentials is indistinguishable here. Thirdly, the $\mathrm{COO}^{-}$peaks at 1600 and $1400 \mathrm{~cm}^{-1}$ (also prominent in Fig. $2 \mathrm{k}$ for AuNP@PCN-222(Cu) and PCN-222(Cu)) dropped their intensity along the reaction course, corroborating the corruption of the MOF structure during $\mathrm{CO}_{2} \mathrm{RR}$ as seen by electron microscopies. As for PCN-222(Cu), the in-situ IR spectra in Fig. $6 \mathrm{c}$ display no evident absorptions from the $\mathrm{CO}_{2} \mathrm{RR}$ intermediates due to either the lack of signal enhancement from the localized surface plasmon resonance (LSPR) of $\mathrm{Au}$, or the overall low $\mathrm{CO}_{2} \mathrm{RR}$ performance of the catalyst.

Mechanistic investigations using density functional theory calculations. It is generally accepted that $\mathrm{C}_{2+}$ products are produced through $\mathrm{C}-\mathrm{C}$ coupling of $\mathrm{CO}^{*}$ at two adjacent copper sites $^{42}$. However, the closest distance between adjacent copper sites in PCN-222(Cu) is more than $10 \AA$ (Supplementary Fig. 1), which is too far to enable $\mathrm{C}-\mathrm{C}$ coupling ${ }^{21,43-45}$. Thus, the $\mathrm{C}_{2} \mathrm{H}_{4}$ production must either be from $\mathrm{Cu}$ clusters that were reduced out from the metal-organic frameworks (as evidenced by the above microscopic and spectroscopic observations for AuNP@PCN$222(\mathrm{Cu})$ and PCN-222(Cu)), or follow a completely different mechanism involving synergy between $\mathrm{Au}$ and metalloporphyrins (as suggested by the case of AuNN@PCN-222(Cu)).

We surmise that the decreased $\mathrm{C}_{2} \mathrm{H}_{4}$ production and increased $\mathrm{H}_{2}$ yield with time on both AuNP@PCN-222(Cu) and PCN$222(\mathrm{Cu})$ may be related to maturing of the $\mathrm{Cu}$ nanoparticles reduced out from the metalloporphyrins during $\mathrm{CO}_{2} \mathrm{RR}$, as multicrystalline $\mathrm{Cu}$ crystallites with rich facets and grain boundaries are known to favor $\mathrm{C}_{2+}$ production ${ }^{46-48}$.

To help understand the improved $\mathrm{C}_{2+}$ selectivity and catalytic stability witnessed on AuNN@PCN-222(Cu), we employed a simplified model of the essential catalyst module by placing the $\operatorname{TCPP}(\mathrm{Cu})$ ligand next to a planar $\mathrm{Au}_{12}$ cluster (Supplementary Fig. 17). By modulating the distance between the TCPP $(\mathrm{Cu})$ molecule and $\mathrm{Au}_{12}$ cluster from 3 to $4.5 \AA$, we found the lowest energy of the two-body system at $3.5 \AA$ (Supplementary Fig. 17d). Therefore, we used the TCPP $(\mathrm{Cu})-\mathrm{Au}_{12}$ model with a distance of $3.5 \AA$ for subsequent calculations and compared it with the standalone TCPP $(\mathrm{Cu})$. Furthermore, we fixed the four carboxylic groups of TCPP in a steady position so as to mimic their presence in the MOF framework. This treatment is important since the ligand in the MOF is relatively constrained when compared to the free molecule.

We then performed DFT calculations on the configuration and energetics of key intermediates involved in the $\mathrm{C} 1$ and $\mathrm{C} 2$ routes. For $\mathrm{C} 1$, we considered ${ }^{*} \mathrm{CO} \rightarrow{ }^{*} \mathrm{CHO} \rightarrow{ }^{*} \mathrm{CHOH}$. For $\mathrm{C} 2$, we considered ${ }^{*} \mathrm{CO} \rightarrow{ }^{*} \mathrm{CHO} \rightarrow{ }^{*} \mathrm{CO}-\mathrm{CHO}^{42,49}$. On TCPP $(\mathrm{Cu})$, the formation energy of ${ }^{*} \mathrm{CO} \rightarrow{ }^{*} \mathrm{CHO}$ is $1.53 \mathrm{eV}$ (Fig. 7a). After geometry optimization, both ${ }^{*} \mathrm{CO}$ and ${ }^{*} \mathrm{CHO}$ adsorb on top of the $\mathrm{Cu}$ site through $\mathrm{C}$-terminus (with the $\mathrm{C}$ - $\mathrm{Cu}$ distances of 3.030 and $1.927 \AA$, respectively), imposing negligible impact on the $\mathrm{TCPP}(\mathrm{Cu})$ ring structure that keeps planar (Supplementary Fig. 18). Reducing ${ }^{*} \mathrm{CHO}$ to ${ }^{*} \mathrm{CHOH}$ is energetically favorable by $-0.53 \mathrm{eV}$. On TCPP $(\mathrm{Cu})$, because each TCPP $(\mathrm{Cu})$ module can 


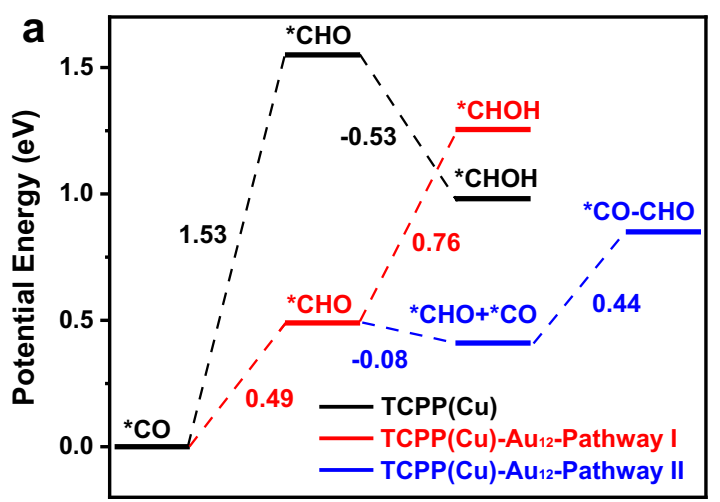

Reaction Coordinates
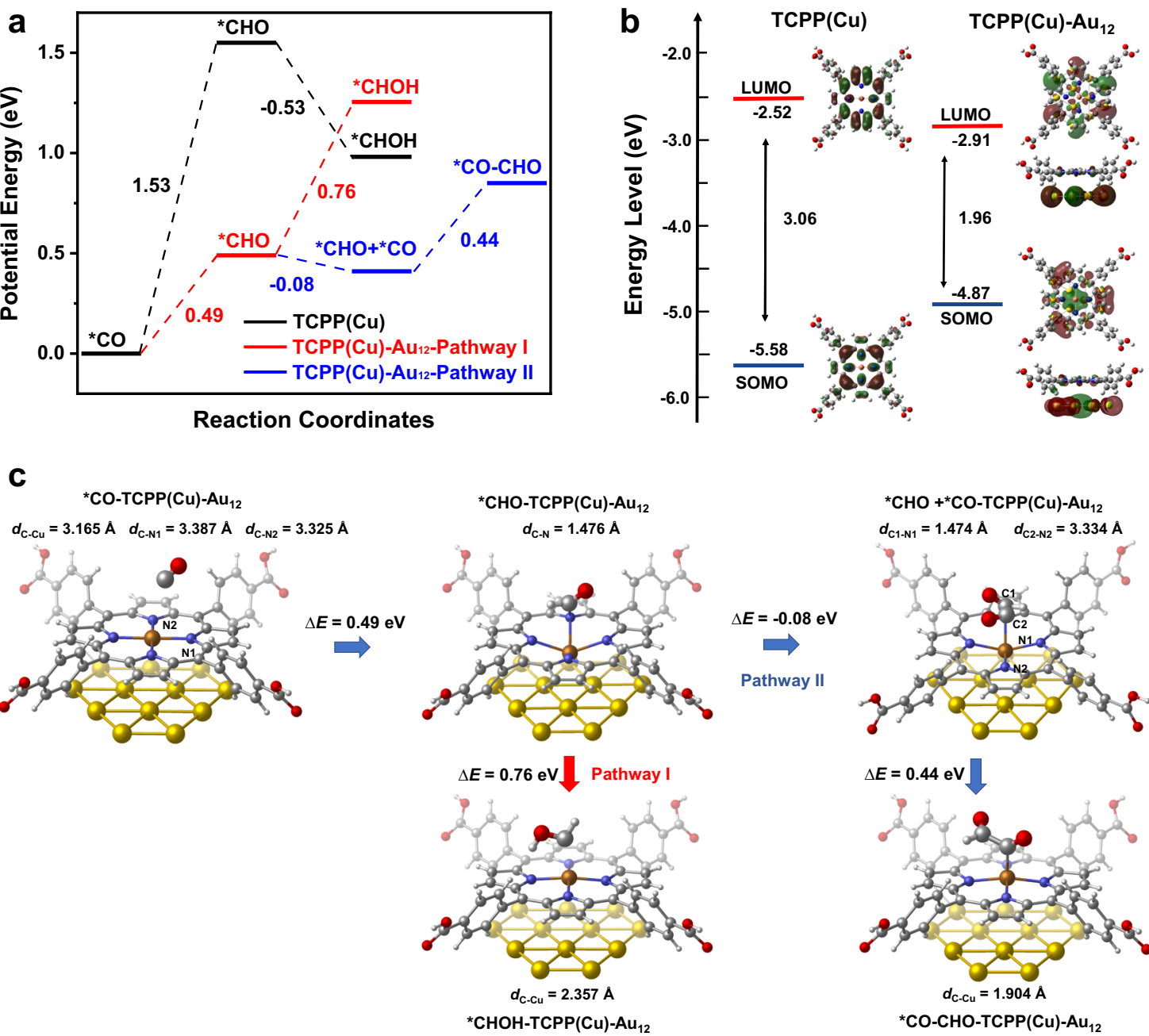
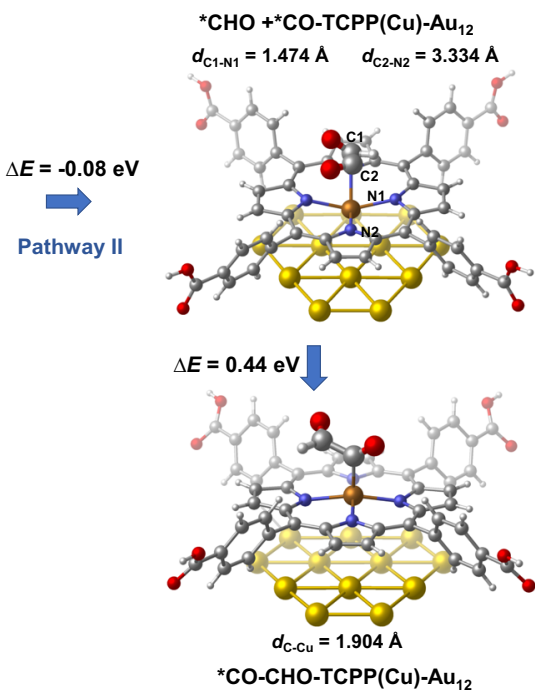

Fig. 7 DFT calculations of the configuration and energetics of key intermediates involved in the C1 and C2 paths. a The formation energy of key intermediates along with the reaction coordinates for $\operatorname{TCPP}(\mathrm{Cu})$ and $\mathrm{TCPP}(\mathrm{Cu})-\mathrm{Au}_{12}$. b Calculated energy levels of HOMO and LUMO for TCPP(Cu) and $\operatorname{TCPP}(\mathrm{Cu})-\mathrm{Au}_{12}$. c Configuration of intermediates absorption on TCPP(Cu)-Au12. The colors are $\mathrm{C}$ in silver, $\mathrm{H}$ in white, $\mathrm{O}$ in red, $\mathrm{N}$ in blue, $\mathrm{Au}$ in yellow, and $\mathrm{Cu}$ in orange.

only provide one catalytic center for $\mathrm{CO}_{2}$ activation at a time, the $\mathrm{C}-\mathrm{C}$ coupling is unfeasible.

The scenario on $\operatorname{TCPP}(\mathrm{Cu})-\mathrm{Au}_{12}$ is quite different, where $\mathrm{C}-\mathrm{C}$ coupling becomes possible (Fig. 7a). Beyond ${ }^{*} \mathrm{CHO}$, both the aforementioned $\mathrm{C} 1$ and $\mathrm{C} 2$ paths are feasible, while competing with each other. On $\operatorname{TCPP}(\mathrm{Cu})-\mathrm{Au}_{12}$, the formation energy of ${ }^{*} \mathrm{CHO}$ from ${ }^{*} \mathrm{CO}$ is $0.49 \mathrm{eV}$, significantly lower than $1.53 \mathrm{eV}$ on $\mathrm{TCPP}(\mathrm{Cu})$. Mullikan Charge analysis shows that the $\mathrm{Au}_{12}$ substrate formally donates 0.038 electrons to $\mathrm{Cu}$ (Table S4), which weakens the $\mathrm{Cu}-\mathrm{N}$ binding and enhances the adsorption of both ${ }^{*} \mathrm{CO}$ and ${ }^{*} \mathrm{CHO}$ (Table S5) that facilitates subsequent reaction cascade.

Different from the case of TCPP $(\mathrm{Cu})$, the adsorbed CO slightly deviates from the top of the $\mathrm{Cu}$ site, interacting with the two nearby $\mathrm{N}$ atoms (as shown in Fig. 7c with the $\mathrm{C}-\mathrm{Cu}, \mathrm{C}-\mathrm{N} 1$, and C-N2 distances of $3.165,3.387$, and $3.325 \AA$, respectively). In the next step, ${ }^{*} \mathrm{CHO}$ moves to the $\mathrm{N}$ site rather than residing on the $\mathrm{Cu}$ site, forming a C-N bond with a distance of $1.476 \AA$ (Fig. 7c, middle panel). Simultaneously, the $\mathrm{Cu}-\mathrm{N}_{4}$ motif undergoes an out-of-plane displacement toward the $\mathrm{Au}$ plane, freeing the $\mathrm{Cu}$ center to accept another Au-generated $\mathrm{CO}$ in affording the coadsorption of ${ }^{*} \mathrm{CO}$ and ${ }^{*} \mathrm{CHO}$ with an exothermic energy difference of $-0.08 \mathrm{eV}$. Subsequently, C-C coupling occurs by bridging the two intermediates to form ${ }^{*} \mathrm{CO}-\mathrm{CHO}$ with a surmountable energy of $0.44 \mathrm{eV}$ (Fig. 7c Pathway II). The existence of ${ }^{*} \mathrm{CO}-\mathrm{CHO}$ intermediate has been confirmed by operando IR at $1578 \mathrm{~cm}^{-1}$, which also explains the fast consumption of $\mathrm{CO}_{\text {atop }}$ on $\mathrm{Au}$ at $2108 \mathrm{~cm}^{-1}$. Energetically, the $\mathrm{C} 1$ route via $* \mathrm{CHOH}$ cannot compete with $\mathrm{C}-\mathrm{C}$ coupling due to its high formation energy of $0.76 \mathrm{eV}$ (Fig. 7c Pathway I).

The $\mathrm{N}$-site catalyzed ${ }^{*} \mathrm{CO}$ reduction to ${ }^{*} \mathrm{CHO}$ was unexpected, because usually only the metal center of a macrocycle molecule is responsible for the catalytic activity. Here the weakened $\mathrm{Cu}-\mathrm{N}$ interaction and the transition from $\mathrm{D}_{4 \mathrm{~h}}$ to $\mathrm{C}_{4 \mathrm{v}}$ symmetry at the metal center due to AuNN insertion and intermediates adsorption is postulated as the underlying reason for the emerging catalytic activity of the $\mathrm{N}$ site. On top of that, AuNN introduced into the MOF interior would further increase the concentration of CO trapped inside the MOF tunnels, due to the spatial confinement effect ${ }^{50,51}$. Such increase in $\mathrm{CO}$ concentration would not only improve the probability of $\mathrm{C}-\mathrm{C}$ coupling when the active sites are brought to sufficient proximity, but also boost the $\mathrm{CO}_{2} \mathrm{RR}$ kinetics ${ }^{52}$.

To testify the role of the MOF framework in promoting $\mathrm{C}-\mathrm{C}$ coupling, we further conducted control experiments by loading $\operatorname{TCPP}(\mathrm{Cu})$ molecules onto $\mathrm{Au}$ nanorods/nanoparticles that are lack of spatial confinement and compared their $\mathrm{CO}_{2} \mathrm{RR}$ performance with that of AuNN-PCN-222(Cu) under the same 
electrolytic condition (Supplementary Fig. 19). In both cases, apart from a small amount of $\mathrm{C}_{2} \mathrm{H}_{4}, \mathrm{CO}$ and $\mathrm{H}_{2}$ constituted the main reduction products, implying the $\mathrm{Au}$ nanostructures and $\operatorname{TCPP}(\mathrm{Cu})$ functioned separately. Collectively, both the experimental observations and DFT calculations corroborate that introducing AuNN into the framework of PCN-222(Cu) enables to boost $\mathrm{C}_{2}$ production.

Ligand-to-metal charge transfer (LMCT) that readily reduces the $\mathrm{Cu}$ site in organometallic compounds has been often perceived as the cause of MOF destruction during $\mathrm{CO}_{2} \mathrm{RR}^{48,49}$. Such a process is plausible because the electronic structure of single occupied molecular orbital (SOMO) and lowest unoccupied molecular orbital (LUMO) indicates that the $\mathrm{Cu}^{2+}$ can be easily reduced. Therefore, in AuNP@PCN-222(Cu) and PCN-222 $(\mathrm{Cu})$ the centric $\mathrm{Cu}$ atom can be readily reduced and dissociated from the porphyrin ring, forming clusters and particles. By contrast, with $\mathrm{Au}$ support the frontier orbitals of TCPP $(\mathrm{Cu})-\mathrm{Au}_{12}$ move to $\mathrm{Au}$, allowing the charge conductance to bypass the LMCT process, but directly hop from Au to the metalloporphyrin center to attend the PCET process. This is especially for the case of AuNN@PCN-222(Cu) where the MOF skeleton is partially cleaved and the conducting pathway along the node-linker network is broken. Such electron conductance ability of Au provides extra protection of the catalyst center, which explains the significantly extended stability as observed experimentally.

\section{Discussion}

In this study, Zirconium-based PCN-222 MOFs comprising metalloporphyrin $\mathrm{Cu}$ centers and impregnated $\mathrm{Au}$ nanoneedles were successfully synthesized by exploiting the ligand carboxylates as the reducing agent. Compared to the same MOF structure with surface-deposited $\mathrm{Au}$ nanoparticles and the one without Au moieties, AuNN@PCN-222(Cu) demonstrated significantly improved ethylene production up to an $\mathrm{FE}$ of $52.5 \%$, whereas AuNP@PCN-222(Cu) and PCN-222(Cu) produced mainly $\mathrm{CO}$ and $\mathrm{H}_{2}$, respectively. More impressive, AuNN@PCN$222(\mathrm{Cu})$ manifested better structural stability during $\mathrm{CO}_{2} \mathrm{RR}$, despite the incoherent reticular network.

Through extensive post-electrolytic and operando characterizations, in conjunction with DFT modeling, the enhanced C-C coupling on AuNN@PCN-222(Cu) was ascribed to a tandem mechanism, where $\mathrm{CO}$ generated from the impregnated $\mathrm{Au}$ nanoneedles are adducted to ${ }^{*} \mathrm{CHO}$ on the metalloporphyrins with Au-activated $\mathrm{N}$ motifs. Additionally, its enhanced structural stability during $\mathrm{CO}_{2} \mathrm{RR}$ can be attributed to an altered charge conduction path bypassing the MOF reticular network. By impregnating metal nanostructures into the PCN framework and activating the metalloporphyrin centers, this study sheds new light on boosting the $\mathrm{C}_{2+}$ selectivity and catalytic stability by exquisite catalyst design and synthesis.

\section{Methods}

Synthesis of PCN-222(M). A traditional solvothermal reaction method was used to synthesize PCN-222(M) $(\mathrm{M}=\mathrm{H}$ or $\mathrm{Cu}) . \mathrm{ZrOCl}_{2} \cdot 8 \mathrm{H}_{2} \mathrm{O}(30 \mathrm{mg})$, M-TCPP (tetrakis(4-carboxyphenyl)porphyrin, $\mathrm{M}=\mathrm{H}$ or $\mathrm{Cu}, 10 \mathrm{mg}$ ), and benzoic acid $(280 \mathrm{mg})$ in a mixed solution of DMF (N,N-dimethyl formamide, $10 \mathrm{~mL}$ ) and DIwater $(100 \mu \mathrm{L})$ were ultrasonically dissolved in a $20 \mathrm{~mL}$ Pyrex vial. The mixture was heated at $90{ }^{\circ} \mathrm{C}$ for $8 \mathrm{~h}$ in an oil bath with stirring kept during the whole reaction. Afterward, the mixture was cooled down in the water and then centrifuged four times with DI-water and ethanol $(8600 \mathrm{~g}, 15 \mathrm{~min})$. Finally, the product was dissolved into acetone for a week to remove any guest molecules in pores. The dark purple powder obtained after centrifugation and drying were then collected for further use.

Synthesis of AuNN@PCN-222(Cu).10 mg of the above-synthesized PCN$222(\mathrm{Cu})$ was ultrasonically dissolved into $100 \mathrm{~mL}$ DI-water buffered with $10 \mathrm{~mL}$ $0.1 \mathrm{M} \mathrm{KHCO}_{3}$ for controlling the $\mathrm{pH}$ (solution A). Then, $100 \mu \mathrm{L}$ of the $\mathrm{HAuCl}_{4}$ aqueous solution $\left(0.05 \mathrm{~mol} \mathrm{~L}^{-1}\right)$ was diluted into $50 \mathrm{~mL} \mathrm{DI}$-water and slowly added to solution $\mathrm{A}$ at a rate of one milliliter per minute. Under the mild acidic condition, $\mathrm{Au}^{3+}$ was reduced by carboxylates contained in the MOF ligands and crystallized into nanoneedles. The amount of Au nanoneedles can be adjusted by varying the added volume of $\mathrm{HAuCl}_{4}$. The final product was collected upon centrifugation and drying.

Synthesis of AuNP@PCN-222(Cu).10 mg PCN-222(Cu) was ultrasonically dissolved in $100 \mathrm{~mL}$ ethanol with the addition of $100 \mu \mathrm{L} \mathrm{HAuCl}_{4}$ aqueous solution $\left(0.05 \mathrm{~mol} \mathrm{~L}^{-1}\right)$. After stirring for $30 \mathrm{~min}, 0.5 \mathrm{~mL} \mathrm{NaBH}_{4}$ ethanol solution $\left(50 \mathrm{mmol} \mathrm{L}^{-1}\right)$ was added to reduce $\mathrm{Au}^{3+}$ into nanoparticles deposited on the MOF surface quickly. After continuously stirring for another ten minutes, the product was collected by centrifugation, followed by freeze-drying overnight.

Electrochemical measurements. The electrochemical $\mathrm{CO}_{2} \mathrm{RR}$ experiments were carried out in a traditional airtight $\mathrm{H}$-cell controlled with an electrochemical workstation (CHI760E). The H-cell used glassy carbon as a working electrode separated from a Pt counter electrode by a Nafion 115 membrane. The reaction was carried out in a $\mathrm{CO}_{2}$-saturated aqueous solution of $0.1 \mathrm{M} \mathrm{KHCO}_{3} .4 \mathrm{mg}$ catalyst, and $2 \mathrm{mg}$ ketjen black were ultrasonically dissolved in $1 \mathrm{ml}$ ethanol with $50 \mu \mathrm{L}$ nafion to prepare the catalyst ink. The working electrodes were prepared by dropcasting the catalyst ink on the glassy carbon electrode with a coating area of $\sim 0.2 \mathrm{~cm}^{2}$. High-purity $\mathrm{CO}_{2}$ gas of $20 \mathrm{~cm}^{3} \mathrm{~min}^{-1}$ was supplied to the gas chamber controlled by a digital mass flow controller (Horiba). The gas products were quantitatively analyzed using gas chromatography equipped with both flame ionization and thermal conductivity detectors (Agilent 7890B). All the potentials were converted to RHE, according to the equation $\mathrm{E}$ (vs $\mathrm{RHE})=\mathrm{E}(\mathrm{vs} \mathrm{Ag} / \mathrm{AgCl})+$ $0.059 \mathrm{pH}+0.198$

Operando ATR-SEIRAS measurements. The ATR-SEIRAS measurements were conducted in a two-compartment spectro-electrochemical cell comprising three electrodes, including a Si prism deposited with a layer of $60 \mathrm{~nm}$ Au film as the working electrode, a platinum-wire as the counter electrode, and a standard Ag/ $\mathrm{AgCl}$ electrode as the reference, as is shown in supplementary Fig. 20. The catalyst ink was spray-coated on the working electrode with an electric airbrush. All electrochemical tests were tested in a $0.1 \mathrm{M} \mathrm{KHCO}_{3}$ aqueous solution saturated with a constant $\mathrm{CO}_{2}$ flow and controlled by a $\mathrm{CHI}$ electrochemical workstation (CHI760E). The cathodic potential was swept from $-0.4 \mathrm{~V}$ to $-1.8 \mathrm{~V}$ vs. RHE every $200 \mathrm{mV}$. All the ATR-SEIRAS spectra were acquired using a Fourier Transform Infrared Spectrophotometer (FT-IR, Nicolet iS50, Thermo Fischer scientific.) equipped with a mercury cadmium telluride (MCT) detector. A bare Au film without loading any catalysts was used as the background reference. All spectroscopic measurements performed at a spectral resolution of $4 \mathrm{~cm}^{-1}$ and overlaying of 64 repetitions.

Operando XAS Measurements. Operando XAS spectra of Cu K-edge were acquired at the Shanghai Synchrotron Radiation Facility, Beamline BL11B beamline. All spectra were recorded in the fluorescence mode using a Lytle detector with the energy calibrated using a $\mathrm{Cu}$ foil. The illumination area on the sample was about $200 \times 250 \mu \mathrm{m}^{2}(\mathrm{H} \times \mathrm{V})$. The electron storage ring was operated at $3.5 \mathrm{GeV}$ in the top-up mode with a beam current of $220 \mathrm{~mA}$. A Si(111) double-crystal monochromator with the energy resolution of $\Delta \mathrm{E} / \mathrm{E}=\sim 1.4 \times 10^{-4}$ was used to monochromatize the incident photons. A pair of Rh-coated mirrors at $4 \mathrm{mrad}$ was employed to reject higher harmonics. A two-compartment $\mathrm{H}$ cell was utilized to conduct the electrolysis in $\mathrm{CO}_{2}$-saturated $0.1 \mathrm{M} \mathrm{KHCO}_{3}$ solution, with the sample set at $45^{\circ}$ related to the incident beam. The preparation of electrodes followed the same procedure described in the section of electrochemical measurement. During the measurements $\mathrm{CO}_{2}$ was constantly bubbled into the cell at a fixed flow rate. All spectra were acquired under the potentiostatic mode by sweeping the potential from 0 to $-1.2 \mathrm{~V}^{53}$. Specifically, at $-1.2 \mathrm{~V}$, the current density on AuNN@PCN$222(\mathrm{Cu})$ was $\sim 10 \mathrm{~mA} \mathrm{~cm}^{-2}$, similar to that of the $\mathrm{H}$-cell setup for performance evaluation.

DFT calculations. DFT calculations were performed using the Gaussian 16 program (version A. 03) 54 at the level of PBE0 functional55 with D3 dispersion correction $^{56}$. $\mathrm{Cu}$ and $\mathrm{Au}$ were described by the Stuttgart-Dresden pseudopotential and double- $\xi$ valence (SDD) basis set, while $\mathrm{H}, \mathrm{C}, \mathrm{N}, \mathrm{O}$ were described by the 6 $31 \mathrm{G}(\mathrm{d})$ all-electron basis set. The solvation effect was considered with the continuum solvent model (SMD) with the parameters for water ${ }^{57}$. The time-dependent density functional theory ${ }^{58,59}$ (TD-DFT) was used to predict the frontier molecular orbitals of the $\mathrm{Cu}$-porphyrin w/o $\mathrm{Au}_{12}$ cluster. To investigate the $\mathrm{CO}_{2} \mathrm{RR}$ performance of $\operatorname{TCPP}(\mathrm{Cu})$ and $\mathrm{TCPP}(\mathrm{Cu})-\mathrm{Au}_{12}$ systems, the catalysis center of

$\operatorname{TCPP}(\mathrm{Cu})$ was modeled by cutting the Cu porphyrin structure from single-crystal $\mathrm{X}$-ray diffraction MOF data ${ }^{44}$. The breaking bonds were saturated as benzoic acids to keep the system electrically neutral. Within the available computational cost, the $\mathrm{Au}_{12}$ cluster model was employed to represent gold nanoneedles because its work function is close to bulk $\mathrm{Au}$, and the interatomic distance of $\mathrm{Au}$ atoms in the $\mathrm{Au}_{12}$ cluster is also comparable to that of bulk $\mathrm{Au}$. No significant change of $\mathrm{Au}_{12}$ planar structure was observed in the calculation, legitimizing its representation of the rigid $\mathrm{Au}$ nanoneedles. 


\section{Data availability}

All data generated or analysed during this study are included in this published article (and its Supplementary Information files) or can be obtained from the authors on reasonable request.

Received: 30 August 2021; Accepted: 10 December 2021; Published online: 17 January 2022

\section{References}

1. Wang, G. et al. Electrocatalysis for $\mathrm{CO}_{2}$ conversion: from fundamentals to value-added products. Chem. Soc. Rev. 50, 4993-5061 (2021).

2. AAAS. After Paris: the rocky road ahead. Science 350, 1018-1019 (2015).

3. De Luna, P. et al. What would it take for renewably powered electrosynthesis to displace petrochemical processes? Science 364, eaav3506 (2019).

4. Xiong, L. et al. Breaking the linear scaling relationship by compositional and structural crafting of ternary $\mathrm{Cu}-\mathrm{Au} / \mathrm{Ag}$ nanoframes for electrocatalytic ethylene production. Angew. Chem. Int. Ed. 60, 2508-2518 (2021).

5. Jiang, $\mathrm{K}$. et al. Metal ion cycling of $\mathrm{Cu}$ foil for selective $\mathrm{C}-\mathrm{C}$ coupling in electrochemical CO2 reduction. Nat. Catal. 1, 111-119 (2018).

6. Birdja, Y. Y. et al. Advances and challenges in understanding the electrocatalytic conversion of carbon dioxide to fuels. Nat. Energy 4, 732-745 (2019).

7. Zhang, L. et al. Enhanced cuprophilic interactions in crystalline catalysts facilitate the highly selective electroreduction of $\mathrm{CO}_{2}$ to $\mathrm{CH}_{4}$. J. Am. Chem. Soc. 143, 3808-3816 (2021).

8. Kang, X. et al. Quantitative electro-reduction of $\mathrm{CO}_{2}$ to liquid fuel over electro-synthesized metal-organic frameworks. J. Am. Chem. Soc. 142, 17384-17392 (2020)

9. Yang, H. B. et al. Atomically dispersed $\mathrm{Ni}(\mathrm{i})$ as the active site for electrochemical $\mathrm{CO}_{2}$ reduction. Nat. Energy 3, 140-147 (2018)

10. $\mathrm{Ma}, \mathrm{W}$. et al. Electrocatalytic reduction of $\mathrm{CO}_{2}$ to ethylene and ethanol through hydrogen-assisted $\mathrm{C}-\mathrm{C}$ coupling over fluorine-modified copper. Nat. Catal. 3, 478-487 (2020)

11. Arquer, F. P. G. D., Dinh, C.-T., Ozden, A. \& Sargent, E. H. $\mathrm{CO}_{2}$ electrolysis to multicarbon products at activities greater than $1 \mathrm{~A} \mathrm{~cm}^{-2}$. Science 367 , 661-666 (2020).

12. Zhao, K. et al. Selective electroreduction of $\mathrm{CO}_{2}$ to acetone by single copper atoms anchored on N-doped porous carbon. Nat. Commun. 11, 2455 (2020).

13. Wang, $\mathrm{X}$. et al. Efficient electrically powered $\mathrm{CO}_{2}$-to-ethanol via suppression of deoxygenation. Nat. Energy 5, 478-486 (2020).

14. Ozden, A. et al. High-rate and efficient ethylene electrosynthesis using a catalyst/promoter/transport layer. ACS Energy Lett. 5, 2811-2818 (2020).

15. Kibria, M. G. et al. Electrochemical $\mathrm{CO}_{2}$ reduction into chemical feedstocks: from mechanistic electrocatalysis models to system design. Adv. Mater. 31, e1807166 (2019)

16. Dong, Y. et al. Ammonia thermal treatment toward topological defects in porous carbon for enhanced carbon dioxide electroreduction. Adv. Mater. 32, e2001300 (2020)

17. Pan, Y. et al. Design of single-atom $\mathrm{Co}-\mathrm{N}_{5}$ catalytic site: a robust electrocatalyst for $\mathrm{CO}_{2}$ reduction with nearly $100 \% \mathrm{CO}$ selectivity and remarkable stability. J. Am. Chem. Soc. 140, 4218-4221 (2018).

18. Zhang, H. et al. Computational and experimental demonstrations of one-pot tandem catalysis for electrochemical carbon dioxide reduction to methane. Nat. Commun. 10, 3340 (2019)

19. Zhou, X. et al. Molecular scalpel to chemically cleave metal-organic frameworks for induced phase transition. J. Am. Chem. Soc. 143, 6681-6690 (2021).

20. Qiu, X. F., Zhu, H. L., Huang, J. R., Liao, P. Q. \& Chen, X. M. Highly selective $\mathrm{CO}_{2}$ electroreduction to $\mathrm{C}_{2} \mathrm{H}_{4}$ using a metal-organic framework with dual active sites. J. Am. Chem. Soc. 143, 7242-7246 (2021).

21. Majidi, L. et al. 2D copper tetrahydroxyquinone conductive metal-organic framework for selective $\mathrm{CO}_{2}$ electrocatalysis at low overpotentials. Adv. Mater. 33, e2004393 (2021).

22. Kang, X. et al. Electro-reduction of carbon dioxide at low over-potential at a metal-organic framework decorated cathode. Nat. Commun. 11, 5464 (2020).

23. Peng, C. et al. Double sulfur vacancies by lithium tuning enhance $\mathrm{CO}_{2}$ electroreduction to n-propanol. Nat. Commun. 12, 1580 (2021).

24. Nam, D. H. et al. Metal-organic frameworks mediate $\mathrm{Cu}$ coordination for selective $\mathrm{CO}_{2}$ electroreduction. J. Am. Chem. Soc. 140, 11378-11386 (2018).

25. Yao, D. et al. The controllable reconstruction of Bi-MOFs for electrochemical $\mathrm{CO}_{2}$ reduction through electrolyte and potential mediation. Angew. Chem. Int. Ed. 60, 18178-18184 (2021).

26. Ahrenholtz, S. R., Epley, C. C. \& Morris, A. J. Solvothermal preparation of an electrocatalytic metalloporphyrin MOF thin film and its redox hopping charge-transfer mechanism. J. Am. Chem. Soc. 136, 2464-2472 (2014).
27. Van Wyk, A., Smith, T., Park, J. \& Deria, P. Charge-transfer within Zr-based metal-organic framework: the role of polar node. J. Am. Chem. Soc. 140 , 2756-2760 (2018)

28. Rungtaweevoranit, B. et al. Copper nanocrystals encapsulated in Zr-based metal-organic frameworks for highly selective $\mathrm{CO}_{2}$ hydrogenation to methanol. Nano Lett. 16, 7645-7649 (2016).

29. Song, Z. et al. Recent advances in MOF-derived single atom catalysts for electrochemical applications. Adv. Energy Mater. 10, 2001561 (2020).

30. Aiyappa, H. B. et al. MOFs for electrocatalysis: from serendipity to design strategies. Small Methods 3, 1800415 (2019).

31. Pratik, S. M., Gagliardi, L. \& Cramer, C. J. Engineering electrical conductivity in stable Zirconium-based PCN-222 MOFs with permanent mesoporosity. Chem. Mater. 32, 6137-6149 (2020)

32. Yang, T.-H. et al. Probing local donor-acceptor charge transfer in a metal-organic framework via a scanning tunneling microscope. J. Phys. Chem C. 124, 21635-21640 (2020)

33. Yang, F. et al. Tuning internal strain in metal-organic frameworks via vapor phase infiltration for $\mathrm{CO}_{2}$ reduction. Angew. Chem. Int. Ed. 59, 4572-4580 (2020).

34. Guntern, Y. T. et al. Nanocrystal/metal-organic framework hybrids as electrocatalytic platforms for $\mathrm{CO}_{2}$ conversion. Angew. Chem. Int. Ed. 58, 12632-12639 (2019)

35. Volosskiy, B. et al. Metal-organic framework templated synthesis of ultrathin, well-aligned metallic nanowires. ACS Nano 9, 3044-3049 (2015).

36. Vigderman, L. \& Zubarev, E. R. High-yield synthesis of gold nanorods with longitudinal SPR peak greater than $1200 \mathrm{~nm}$ using hydroquinone as a reducing agent. Chem. Mater. 25, 1450-1457 (2013).

37. Maiti, N. C., Mazumdar, S. \& Periasamy, N. J- and H-aggregates of porphyrinsurfactant complexes: time-resolved fluorescence and other spectroscopic studies. J. Phys. Chem. B. 102, 1528-1538 (1998).

38. Karapinar, D. et al. Electroreduction of $\mathrm{CO}_{2}$ on single-site copper-nitrogendoped carbon material: selective formation of ethanol and reversible restructuration of the metal sites. Angew. Chem. Int. Ed. 58, 15098-15103 (2019).

39. Weng, Z. et al. Active sites of copper-complex catalytic materials for electrochemical carbon dioxide reduction. Nat. Commun. 9, 415 (2018).

40. Chou, T. C. et al. Controlling the oxidation state of the $\mathrm{Cu}$ electrode and reaction intermediates for electrochemical $\mathrm{CO}_{2}$ reduction to ethylene. J. Am. Chem. Soc. 142, 2857-2867 (2020).

41. Perez-Gallent, E., Figueiredo, M. C., Calle-Vallejo, F. \& Koper, M. T. Spectroscopic observation of a hydrogenated CO dimer intermediate during $\mathrm{CO}$ reduction on $\mathrm{Cu}(100)$ electrodes. Angew. Chem. Int. Ed. 56, 3621-3624 (2017).

42. Cheng, T., Xiao, H. \& Goddard, W. A. 3rd Full atomistic reaction mechanism with kinetics for $\mathrm{CO}$ reduction on $\mathrm{Cu}(100)$ from ab initio molecular dynamics free-energy calculations at 298 K. Proc. Natl Acad. Sci. USA 114, 1795-1800 (2017).

43. Morales-Guio, C. G. et al. Improved $\mathrm{CO}_{2}$ reduction activity towards $\mathrm{C} 2+$ alcohols on a tandem gold on copper electrocatalyst. Nat. Catal. 1, 764-771 (2018).

44. Feng, D. et al. Zirconium-metalloporphyrin PCN-222: mesoporous metalorganic frameworks with ultrahigh stability as biomimetic catalysts. Angew. Chem. Int. Ed. 51, 10307-10310 (2012).

45. Feng, D. et al. Construction of ultrastable porphyrin $\mathrm{Zr}$ metal-organic frameworks through linker elimination. J. Am. Chem. Soc. 135, 17105-17110 (2013).

46. Jung, $\mathrm{H}$. et al. Electrochemical fragmentation of $\mathrm{Cu}_{2} \mathrm{O}$ nanoparticles enhancing selective $\mathrm{C}-\mathrm{C}$ coupling from $\mathrm{CO}_{2}$ Reduction Reaction. J. Am. Chem. Soc. 141, 4624-4633 (2019).

47. Cheng, T., Xiao, H. \& Goddard, W. A. Nature of the active sites for CO reduction on copper nanoparticles; suggestions for optimizing performance. $J$. Am. Chem. Soc. 139, 11642-11645 (2017).

48. Jeon, H. S. et al. Selectivity control of $\mathrm{Cu}$ nanocrystals in a gas-fed flow cell through $\mathrm{CO}_{2}$ pulsed electroreduction. J. Am. Chem. Soc. 143, 7578-7587 (2021).

49. Xiao, H., Cheng, T., Goddard, W. A. 3rd \& Sundararaman, R. Mechanistic explanation of the $\mathrm{pH}$ dependence and onset potentials for hydrocarbon products from electrochemical reduction of $\mathrm{CO}$ on $\mathrm{Cu}$ (111). J. Am. Chem. Soc. 138, 483-486 (2016).

50. Yang, K. D. et al. Morphology-directed selective production of ethylene or ethane from $\mathrm{CO}_{2}$ on a $\mathrm{Cu}$ mesopore electrode. Angew. Chem. Int. Ed. 56, 796-800 (2017).

51. Zhuang, T. T. et al. Copper nanocavities confine intermediates for efficient electrosynthesis of C3 alcohol fuels from carbon monoxide. Nat. Catal. 1, 946-951 (2018).

52. $\mathrm{Li}$, Y. et al. Promoting $\mathrm{CO}_{2}$ methanation via ligand-stabilized metal oxide clusters as hydrogen-donating motifs. Nat. Commun. 11, 6190 (2020) 
53. Sun, H. et al. Promoting ethylene production over a wide potential window on $\mathrm{Cu}$ crystallites induced and stabilized via current shock and charge delocalization. Nat. Commun. 12, 6823 (2021).

54. M. J. Frisch, G. W. T., et al. Gaussian 16, Revision A.03, Gaussian, Inc., Wallingford CT (2016)

55. Adamo, C. \& Barone, V. Toward reliable density functional methods without adjustable parameters: the PBE0 model. J. Chem. Phy 110, 6158-6170 (1999).

56. Grimme, S., Antony, J., Ehrlich, S. \& Krieg, H. A consistent and accurate ab initio parametrization of density functional dispersion correction (DFT-D) for the 94 elements H-Pu. J. Chem. Phy 132, 154104 (2010).

57. Marenich, A. V., Cramer, C. J. \& Truhlar, D. G. Universal solvation model based on solute electron density and on a continuum model of the solvent defined by the bulk dielectric constant and atomic surface tensions. J. Phys. Chem. B 113, 6378-6396 (2009).

58. Casida, M. E., Jamorski, C., Casida, K. C. \& Salahub, D. R. Molecular excitation energies to high-lying bound states from time-dependent densityfunctional response theory: characterization and correction of the timedependent local density approximation ionization threshold. J. Chem. Phy 108, 4439-4449 (1998).

59. Matsuzawa, N. N., Ishitani, A., Dixon, D. A. \& Uda, T. Time-dependent density functional theory calculations of photoabsorption spectra in the vacuum ultraviolet region. J. Phys. Chem. A 105, 4953-4962 (2001)

\section{Acknowledgements}

This work is supported by National Natural Science Foundation of China (Nos. 22072101, 22075193, 21903058), Natural Science Foundation of Jiangsu Province (No. BK20211306), National Key R\&D Program of China (Grant no. 2020YFB1505703 and 2020YFA0406103), Natural Science Foundation of Jiangsu Higher Education Institutions (SBK20190810), Six Talent Peaks Project in Jiangsu Province (No. TD-XCL-006), and the Priority Academic Program Development (PAPD) of Jiangsu Higher Education Institutions. This work was supported by the Project of Jiangsu Engineering Laboratory of New Materials for Sewage Treatment and Recycling, Soochow University (No. SDGC2126). This work was also partly supported by the Collaborative Innovation Center of Suzhou Nano Science \& Technology. W.A.G. gratefully acknowledges support from the Liquid Sunlight Alliance, which is supported by the U.S. Department of Energy, Office of Science, Office of Basic Energy Sciences, Fuels from Sunlight Hub under award number DE-SC0021266.

\section{Author contributions}

Y.P. conceived the idea for the project and led the project. X.X. and X.Z. conducted the experiments and performed the data analysis. M.X., B.M., T.C., and W.A.G performed the DFT Calculations. J.Z., J.X., and S.L. contributed the EXAFS analysis. L.X., H.S., Q.M., and Z.D. analysed the results and reviewed the paper. M.H.R. contributed the CsTEM characterization. Y. L. prepared TCPP $(\mathrm{Cu})$. All authors discussed the results and commented on the manuscript.

\section{Competing interests}

The authors declare no competing interests.

\section{Additional information}

Supplementary information The online version contains supplementary material available at https://doi.org/10.1038/s41467-021-27768-6.

Correspondence and requests for materials should be addressed to Tao Cheng, William A. Goddard III or Yang Peng.

Peer review information Nature Communications thanks Zhong-Huai Hou and the other anonymous reviewer(s) for their contribution to the peer review of this work.

Reprints and permission information is available at http://www.nature.com/reprints

Publisher's note Springer Nature remains neutral with regard to jurisdictional claims in published maps and institutional affiliations.

\section{c) (1)}

Open Access This article is licensed under a Creative Commons Attribution 4.0 International License, which permits use, sharing, adaptation, distribution and reproduction in any medium or format, as long as you give appropriate credit to the original author(s) and the source, provide a link to the Creative Commons license, and indicate if changes were made. The images or other third party material in this article are included in the article's Creative Commons license, unless indicated otherwise in a credit line to the material. If material is not included in the article's Creative Commons license and your intended use is not permitted by statutory regulation or exceeds the permitted use, you will need to obtain permission directly from the copyright holder. To view a copy of this license, visit http://creativecommons.org/ licenses/by/4.0/.

(c) The Author(s) 2022 